\title{
The Public Health Implications of Melioidosis
}

\author{
Timothy J.J. Inglis ${ }^{1}$ and Anastácio Q. Sousa ${ }^{2}$ \\ ${ }^{I}$ Division of Microbiology \& Infectious Diseases, PathWest Laboratory Medicine WA, and Microbiology \& Immunology, School of Biomedical, \\ Biomolecular and Chemical Sciences, University of Western Australia, Queen Elizabeth Medial Centre; Western Australia, Australia; ${ }^{2}$ São Jose \\ Hospital and Tropical Medicine Nucleus, Federal University of Ceará; Fortaleza, Ceará, Brazil
}

\begin{abstract}
Melioidosis, which is caused by the bacterium Burkholderia pseudomallei, is a potentially fatal tropical infection, little known outside its main endemic zone of Southeast Asia and northern Australia. Though it has received more attention in recent years on account of its claimed suitability as a biological weapon agent, the principal threat from melioidosis is a result of naturally occurring events. Occasional case clusters, sporadic cases outside the known endemic zone and infections in unusual demographic groups highlight a changing epidemiology. As melioidosis is the result of an environmental encounter and not person-to-person transmission, subtle changes in its epidemiology indicate a role environmental factors, such as man-made disturbances of soil and surface water. These have implications for travel, occupational and tropical medicine and in particular for risk assessment and prevention. Practical problems with definitive laboratory diagnosis, antibiotic treatment and the current lack of a vaccine underline the need for prevention through exposure avoidance and other environmental health measures. It is likely that the increasing population burden of the tropical zone and extraction of resources from the humid tropics will increase the prevalence of melioidosis. Climate change-driven extreme weather events will both increase the prevalence of infection and gradually extend its main endemic zone.
\end{abstract}

Key-Words: Public Health, melioidosis, epidemiology.

\section{Public Health Data on Melioidosis}

Accurate figures on melioidosis are hard to come by. In many parts of the world, the disease is unknown. Its clinical features are so many, varied and non-specific that there is a danger that an infected patient may go undiagnosed [1]. A further difficulty in reaching an accurate diagnosis of confirmed melioidosis is that it requires an unusual level of diagnostic laboratory expertise. This is lacking even in many developed countries where the infection is not endemic, and in remote parts of countries where the disease is known [2]. A further complicating consideration is its propensity for poorer, rural populations with limited access to health care. Finally, there are very few countries where melioidosis is a notifiable disease. Disease notification to public health authorities ensures consistency of surveillance, but does not guarantee that all cases will necessarily come to the attention of epidemiologists. In Australia, where some states and territories have melioidosis on the list of notifiable diseases, this has led to the development of a standard laboratory case definition of infection [3]. Standardization of public health laboratory methods leads, in turn, to comparability of disease surveillance data between states and cooperative development of diagnostic methods.

\footnotetext{
Received on 10 October 2008; revised 21 January 2009.

Address for correspondence: Dr. Timothy J.J. Inglis. Division of Microbiology \& Infectious Diseases, PathWest Laboratory Medicine WA, Queen Elizabeth II Medical Centre, Nedlands, Western Australia, 6909, Australia. Phone: +618 9346 3461. Fax: +618 9318 1379. Email: tim.inglis@health.wa.gov.au.
}

The Brazilian Journal of Infectious Diseases

2009;13(1):59-66. (C) 2009 by The Brazilian Journal of Infectious Diseases and Contexto Publishing. All rights reserved.

\section{Epidemiology}

Clinical Spectrum

Recognizing that laboratory-based surveillance of melioidosis is patchy, inconsistent and poorly targeted with respect to the most vulnerable at-risk populations; it is still possible to draw an outline of the general epidemiology of infection [4]. The infection is a collection of disease states caused by the Gram-negative bacterial species, Burkholderia pseudomallei (formerly known as Pseudomonas pseudomallei). These conditions include a rapidly fatal Gram-negative septicemia, with or without pneumonia, central nervous system infection, localized abscess formation or soft tissue infection and asymptomatic exposure with seroconversion [5]. These conditions overlap somewhat, since localized infection may spill over to cause systemic infection, and septicemia may result in dissemination to distant tissues in which localized infection occurs. The clinical picture is further complicated by a varied incubation period that varies from 24-48 hours after exposure till septicemia, to late onset disease occurring after an extended period of dormancy. None of the clinical features are specific, pathognomonic indicators of melioidosis, so that the possibility of melioidosis may only be considered when the identity of the infective agent is established by an unsuspecting but alert laboratory scientist. That depends on obtaining a culture of blood, sputum, pus, cerebrospinal or other relevant body fluid. Though reasonably straightforward in laboratories that are familiar with this infection, a first time laboratory encounter with $B$. pseudomallei may not result in a correct identification because some commonly used diagnostic laboratory methods can give incorrect results in up to around $20 \%$ of cases [6]. For this reason, we rely on a costly, polyphasic identification process; but we still have trouble confirming this infection in many cases [7]. 
Geographic Distribution

Authorities recognize that melioidosis is under-diagnosed and may be completely missed in parts of the world where health infrastructure is poorly developed [2]. A clue to the wider distribution of infection comes from occasional reports of international travelers who return to developed countries with melioidosis acquired in other parts of the world [8-10]. The increasing trend towards adventure travel to exotic locations is expected to result in a steady increase in travelrelated melioidosis. In Southeast Asia, most cases have been reported from rural locations in people who have frequent contact with soil and water, such as rice farmers [11]. In northern Australia, where there is no rice cultivation, the majority of reported cases have been in indigenous inhabitants of remote communities, particularly those with diabetes, chronic renal disease or alcohol dependency [12]. When these three co-morbidities are taken together, ethnicity ceases to be an independent risk factor, suggesting that underlying disease is the main contributor to epidemiological risk of established B. pseudomallei infection. The indigenous population of northern Australia and Asian rice farmers have in common a high level of exposure to soil in a disease-endemic zone. Others who are exposed to moist soil and surface water have also been reported to develop melioidosis [13], suggesting that the principal risk of exposure is determined by environmental conditions.

\section{Route of Infection}

The precise means of infection has yet to be determined. Some authorities consider it to be mainly inoculation of contaminated material via skin abrasions or incisions [14]. Others cite the high proportion of helicopter crewmembers who developed pulmonary melioidosis during the Viet Nam war as evidence for inhalation exposure [15]. There is recent laboratory animal evidence that explores respiratory exposure, but the relative importance of this route has still to be resolved [16].

\section{Climatic \& Seasonal Associations}

One of the most interesting aspects of melioidosis epidemiology to emerge in recent years has been an association with extreme weather events. In northern Australia, the acute form of infection is strongly associated with the onset of the summer rainy season [17]. Most septicemic cases occur within a week of the start of the summer rains. In general, cases cluster around severe events, such as the heavy rainfall that occurs when cyclones go through [18]. Though not strictly a weather event, the 2004 Boxing Day tsunami is thought to have caused additional cases of melioidosis around the rim of the Indian Ocean, when many people were forcefully swept through mud and surface water by the tidal wave [19]. Recently, we have documented a possible association between asymptomatic seroconversion and an extreme weather event that occurred in northwestern Australia in 2005 [20]. As the mean annual summer rainfall has more than doubled in these parts of northern Australia over the last two decades, we anticipate an increased melioidosis caseload in years to come if rainfall continues to increase at the current rate.

\section{Transmissibility}

Another notable aspect of melioidosis epidemiology is that the infection only rarely transmits from person to person, despite its ability to cause lung infection. The few instances of direct transmission reported have been as a result of intimate contact between the donor and recipient [21,22].

\section{Outbreaks and Case-Clusters}

Melioidosis is not an infection of frequent outbreaks. In recognized endemic areas, acute infections occur sporadically, with a seasonal bias. The very few outbreaks that have been documented so far are thus the consequence of unusual interactions between a community and its environment. Only three clear-cut human outbreaks have been attributed to a single source, and the common feature was confirmed or likely contamination of a water source: in the two Australian events, it was the drinking water supply of affected communities $[23,24]$. In the Brazilian event, the source was an irrigation dam reservoir into which the infected subjects had dived shortly after the dam filled with early rains [25]. Porcine outbreaks occurred in Queensland after heavy rain and river flooding [26]. Detailed laboratory investigation surrounded all these events and in some attributed the source of infection to a specific environmental source $[23,24]$. It is likely that similar events go unnoticed and uninvestigated in parts of the recognized endemic zone where field investigation tools are lacking. The Brazil outbreak was particularly notable, because it affected a small group of previously healthy children [25]. The explanation for this observation is lacking; it could be due to a particularly high infective dose, an unusually virulent strain of $B$. pseudomallei or a genetic susceptibility. In order to better understand the ecology of melioidosis, field investigation resources need to be made available to the communities where melioidosis case clusters occur.

\section{Environmental Health Investigations}

The limited investigational resources available to public health authorities in those places where melioidosis is emerging or already endemic have to be used sparingly. Even in well-resourced countries such as Australia, the remote location of melioidosis-affected communities and at-risk industrial sites places restrictions on what can be assembled of short notice to investigate a suspected outbreak. A short list of alerts or red flags is provided in Table 1 to assist environmental health investigation planning. These are the situations that are most likely to provide environmental threat assessment data useful to public health authorities. Field investigations over a period of more than 10 years in Western Australia and the Northern Territory have concentrated on a small range of sample types most likely to yield a high return on effort (Figure 1, 
Table 1. Reasons for increased public health melioidosis alert level and recommended actions targeting unusual disease activity in order to maximize disease control and environmental health measures.

\begin{tabular}{|c|c|c|c|}
\hline Reason for alert & Rationale & Action & References \\
\hline Case cluster & $\begin{array}{l}\text { Unusual event, undisclosed cases, } \\
\text { Potential secondary prevention }\end{array}$ & $\begin{array}{l}\text { Case finding } \\
\text { Environmental health investigation } \\
\text { Enhanced laboratory surveillance } \\
\text { Isolate genotyping }\end{array}$ & $23,24,25$ \\
\hline Multiple deaths, septicemic disease & $\begin{array}{l}\text { Unusual severity, clustering, } \\
\text { potential single source }\end{array}$ & As in case cluster & $12,23,24,24$ \\
\hline Pediatric cases & Unusual severity & $\begin{array}{l}\text { Case finding, serosurveillance, } \\
\text { enhanced laboratory surveillance }\end{array}$ & $25,42,43$ \\
\hline Epizootic & Potential herald event & Veterinary \& serosurveillance & $25,26,30$ \\
\hline Previously unknown location & Extension of endemic area & Enhanced laboratory surveillance & $8,9,10$ \\
\hline Dry season septicemic cases & $\begin{array}{l}\text { Unusual event, specific } \\
\text { environmental source }\end{array}$ & $\begin{array}{l}\text { EH investigation, case finding, } \\
\text { serosurveillance }\end{array}$ & 27 \\
\hline
\end{tabular}

Figure 1. Burkholderia environmental sample processing flowchart.

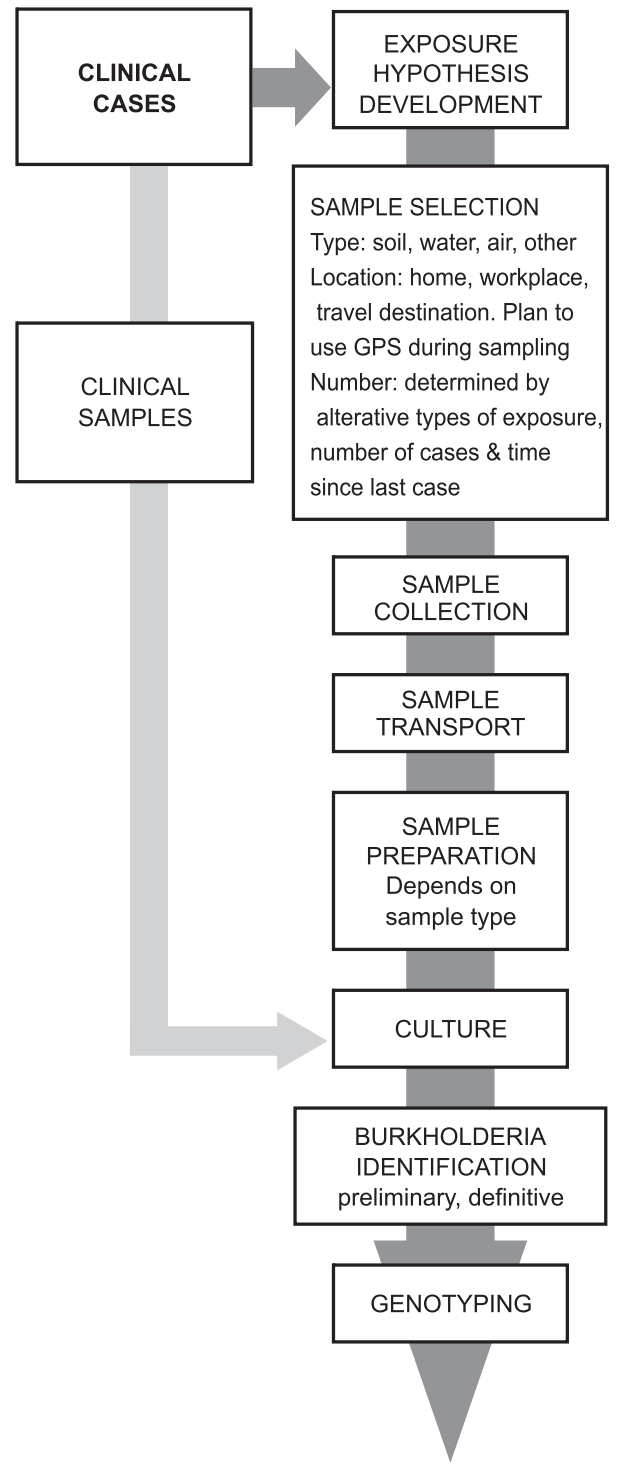

Table 2). It should also be remembered that these methods need prior development and rehearsal by a regional public health reference laboratory in concert with environmental health officers, biologists and public health physicians. Best results will be obtained when all the public health stakeholders are able to prepare, plan, rehearse and deploy as a team effort, as was evidenced by investigations in Western Australia in 1997 and 1998 [23,27], and in Ceará, Brazil in 2004 and 2005 [25]. In both cases, a high degree of interagency cooperation was achieved by exemplary public health leadership and advocacy at an executive level. The aim of a careful field investigation of melioidosis is an understanding of the nature and degree of the environmental hazard, an appreciation of whether it is likely to continue, and if so, what environmental health measures could be taken to reduce the threat of further infection. When field investigations identify a continuing melioidosis threat, they should result in subsequent targeted disease and environmental surveillance [28].

\section{Disease Control Methods \\ Personal Measures}

In the absence of an effective vaccine for melioidosis, the prospect of comprehensive disease control seems a distant reality. However, the predilection of infection for specific high-risk groups in particular locations provides a guide for environmental control methods that can be used with expected benefit. At a personal level, anyone with regular contact with soil or surface water in known endemic locations can be advised about personal precautions to reduce the risk of infection. These include simple personal protective measures such as avoiding skin abrasions, cleaning them thoroughly if they become contaminated with soil or water, and wearing protective equipment such as gloves and suitable clothing for exposure-prone occupations. People with known co-morbidities, such as diabetes or renal disease, need to take special care to apply these measures. 
Table 2. Methods for use in environmental health investigation of melioidosis.

\begin{tabular}{|c|c|c|c|c|c|}
\hline Sample & Dry soil & Wet soil & Water & Air & Other \\
\hline Selection & $\begin{array}{l}\text { Potential exposure } \\
\text { location } \\
5-10 \mathrm{~cm} \text { below surface, } \\
20-30 \mathrm{~cm} \text { below surface } \\
>50 \mathrm{~cm} \text { deep if loose soi }\end{array}$ & $\begin{array}{l}\text { Moist surface soil } \\
\text { Or mud below shallow } \\
\text { Surface water } \\
\text { il }\end{array}$ & $\begin{array}{l}\text { Shallow, permanent or } \\
\text { temporary surface water } \\
\text { Not flowing } \\
\text { May be muddy }\end{array}$ & $\begin{array}{l}\text { Only during } \\
\text { extreme } \\
\text { weather or } \\
\text { other aerosol } \\
\text { events }\end{array}$ & $\begin{array}{l}\text { Root soil, water treatment } \\
\text { equipment, biofilms } \\
\text { IAW exposure hypothesis }\end{array}$ \\
\hline Number & Decide according to exp & xposure hypothesis. Fe & wer samples \& thorough & laboratory proc & cess is better option. \\
\hline Quantity & Circa $100 \mathrm{gm}-1 \mathrm{~kg}$ & Circa 25-100g & $100-500 \mathrm{~mL}$ & $\begin{array}{l}\text { Circa } 10 \mathrm{~mL} \\
\text { filtrate }\end{array}$ & Variable \\
\hline Container & $\begin{array}{l}\text { clean self-seal } \\
\text { plastic bag }\end{array}$ & Screw-top plastic & $\begin{array}{l}\text { Screw-top plastic } \\
\text { No preservative } \\
\text { Fill to lid }\end{array}$ & $\begin{array}{l}\text { Screw-top } \\
20 \mathrm{~mL} \text { sterile }\end{array}$ & Screw-top plastic \\
\hline Transport & $\begin{array}{l}\text { To lab within } 48 \mathrm{hr} \text {, } \\
\text { with thermal } \\
\text { insulation if by air }\end{array}$ & $\begin{array}{l}\text { To lab within } 24 \mathrm{hr} \text {, } \\
\text { with thermal } \\
\text { insulation if by air }\end{array}$ & $\begin{array}{l}\text { To lab within } 24 \mathrm{hr} \text {, } \\
\text { with thermal } \\
\text { insulation if by air }\end{array}$ & $\begin{array}{l}\text { To lab within } \\
\text { 24hr thermal } \\
\text { insulation }\end{array}$ & $\begin{array}{l}\text { To lab within } 24 \mathrm{hr} \text {, with } \\
\text { thermal insulation if by air }\end{array}$ \\
\hline Preparation & $\begin{array}{l}\text { Sieve } 100 \mathrm{~g} \text { for } \mathrm{AMF}^{\mathrm{a}} \\
25 \mathrm{~g} \text { in } 100 \mathrm{~mL} \mathrm{SDW}^{\mathrm{b}} \\
\text { overnight then } 5 \mathrm{~mL} \\
\text { at sample surface }\end{array}$ & $\begin{array}{l}25 \mathrm{~g} \text { in } 100 \mathrm{~mL} \text { SDW } \\
\text { overnight then } 5 \mathrm{~mL} \\
\text { at sample surface }\end{array}$ & $\begin{array}{l}\text { Allow } 100 \mathrm{~mL} \text { aliquot } \\
\text { to settle overnight, then } \\
6 \mathrm{~mL} \text { sample at surface } \\
\text { filter remainder: } \\
0.45 \mu \mathrm{m} \text { pore, } \\
\text { then } 0.22 \mu \mathrm{m} \text { pore }\end{array}$ & $\begin{array}{l}\text { If }>10 \mathrm{~mL} \text {, split } \\
\text { in two, sonicate } \\
\text { one portion }\end{array}$ & $\begin{array}{l}\text { According to sample type } \\
\text { te }\end{array}$ \\
\hline $\begin{array}{l}\text { Initial } \\
\text { culture }\end{array}$ & $\begin{array}{l}1 \mathrm{~mL}^{-} \text {onto BPSA } \\
\text { and ASA } \\
4 \mathrm{~mL} \text { into } 50 \mathrm{~mL} \\
\mathrm{GTSB}^{\mathrm{e}} \text { broth } \\
\text { incubate at } \\
37^{\prime} \mathrm{C} \times 48 \mathrm{hr}\end{array}$ & $\begin{array}{l}1 \mathrm{~mL} \text { onto BPSA } \\
\text { and ASA } \\
4 \mathrm{~mL} \text { into } 50 \mathrm{~mL} \\
\text { GTSB broth } \\
\text { incubate at } \\
37^{\prime} \mathrm{C} \times 48 \mathrm{hr}\end{array}$ & $\begin{array}{l}1 \mathrm{~mL} \text { onto BPSA } \\
\text { and ASA } \\
4 \mathrm{~mL} \text { into } 50 \mathrm{~mL} \\
\text { GTSB broth } \\
\text { incubate at } \\
37^{\prime} \mathrm{C} \times 48 \mathrm{hr}\end{array}$ & $\begin{array}{l}\text { 1mLontoBPSA, } \\
\text { ASA and FBA } \\
4 \mathrm{~mL} \text { into } 50 \mathrm{~mL} \\
\text { GTSB broth } \\
\text { incubate at } \\
37^{\prime} \mathrm{C} \times 48 \mathrm{hr}\end{array}$ & According to sample type \\
\hline $\begin{array}{l}\text { Extra } \\
\text { cultures }\end{array}$ & $\begin{array}{l}\text { Digest of AMF } \\
\text { contents to } \\
\text { BPSA and GTSB }\end{array}$ & $\begin{array}{l}\text { Circa } 1 \mathrm{~mL} \text { soil } \\
\text { to GTSB }\end{array}$ & $\begin{array}{l}0.22 \text { um filter membrane } \\
\text { to BPSA }\end{array}$ & $\begin{array}{l}\text { Repeat for } \\
\text { sonicate }\end{array}$ & According to sample type \\
\hline Prelim ID & \multicolumn{5}{|c|}{$\mathrm{GNB}^{\mathrm{h}}$, oxidase pos, GM R $\mathrm{R}^{\mathrm{i}}$} \\
\hline Definitive ID & \multicolumn{5}{|c|}{ LpxO PCR ${ }^{\mathrm{j}}, \mathrm{RecA}$ PCR \& sequence, GLC-FAMEk ${ }^{\mathrm{k}}$ analysis } \\
\hline Genotyping & \multicolumn{5}{|c|}{ PFGE, VNTR or MLST ${ }^{1}$ to refine connection between environmental \& clinical isolates } \\
\hline
\end{tabular}

Abbreviations: a. AMF = arbuscular mycorrhizal fungi; b. SDW = sterile distilled water; c. BPSA = Burkholderia pseudomallei selective agar; d. ASA = Ashdown's selective agar; e. GTSN = Gentamicin triptic soya broth; f. FBA = fresh horse blood agar; g. ID = identification; h. GNB $=$ Gram negative bacillus; i. GM R = Gentamicin resistant; $\mathrm{j}$. PCR = polymerase chain reaction; $\mathrm{k}$. GLC-FAME $=$ gas liquid chromatographfatty acid methyl ester; 1 . PFGE, VNTR or MLST = genotyping by pulsed-field gel electrophoresis, variable number tandem repeat or multi locus sequence typing.

\section{Community Measures}

At a community level, sporadic infection is difficult to prevent completely, but repetition of true outbreaks may be avoided by careful chlorination or chloramination of the drinking water supply [29]. The occurrence of animal die-off in domestic livestock needs to be thoroughly investigated by veterinary pathologists as a possible sentinel event for subsequent human infection. The porcine melioidosis case cluster in Queensland may thus have acted as an awareness raiser among veterinary and human health authorities, anticipating a whole-health approach to melioidosis control efforts in more recent years [26]. It is possible that a livestock die-off in the Tejuçuoca municipality of Ceará prior to the small melioidosis case cluster of 2004 might have been a melioidosis epizootic [25], but the absence of veterinary analysis of this livestock problem means that this interpretation remains speculative. Sporadic animal cases of melioidosis are well recognised and may have occurred elsewhere in Brazil, from recent anecdotal accounts.

\section{Environmental Management}

A fascinating alternative approach is suggested by data obtained from repeated environmental investigations in Western Australia that have consistently returned $B$. pseudomallei negative soil and water cultures from a location that was previously positive and which generated a 25 year long series of caprine infections plus one human infection [30,31]. At this location, culture negativity coincided with the 
restoration of native vegetation and removal of chemical fertilizers (urea and superphosphate), both of which are substrates for B. pseudomallei. Interestingly, locations in Eastern Malaysia upriver from melioidosis endemic communities have both no evidence of clinical disease or asymptomatic seroconversion, nor do they have $B$. pseudomallei in their organically-cultivated rice fields (personal communication, AKR Hassan). This data is consistent with promotion of environmental risk by modern intensive cultivation methods, remediable by restoration of native flora. Though this interpretation is provisional, it may be worth considering in rural locations that become hyperendemic or which have a persistent association with fatal infection. Specific investigations are currently under way focusing on rice cultivation and rubber plantations, since workers in both types of crop cultivation are at increased risk of melioidosis.

\section{Occupational Risk}

Outdoor Occupations

Rural workers engaged in regular exposure to moist soil or surface water are known to be at increased melioidosis risk. These include rice farmers using traditional methods [11]. The risk can be reduced for this group by mechanization or more cheaply by wearing protective footwear. Lowland rice cultivation in flooded paddy fields is probably the highest form of risk for this group. Rubber tree tappers have been shown to be at risk of melioidosis and B. pseudomallei can be found in the soil under rubber trees [32], but little work has been done to calculate the relative risk of specific rubber cultivation activities and its possible seasonal variability. More detailed studies would allow specific preventive measures to be recommended. Recent work on the melioidosis risk of mineworkers suggests that at a mine site with identifiable $B$. pseudomallei contamination, a combination of careful occupational health measures, dust suppression and other environmental management measures mitigates infection risk [20]. However, excavation activities on a large industrial site in the humid tropics may result in exposure of some staff to concentrated biological aerosols, particularly during heavy rainfall. Suitable personal protective measures have yet to be designed and evaluated for workers in these tropical industrial environments. Possibly, the most unpredictable melioidosis risks are those to which people engaged in adventure travel may be exposed. This group includes overland trekkers, explorers of the remote tropics, field workers, exploratory mining engineers, eco-tourists, their guides, and military personnel engaged in training expeditions [8-10]. As their specific exposure to previously unidentified $B$. pseudomallei contaminated environments is difficult to anticipate, quantify or locate after the event, only general preventive personal advice can be given prior to departure. Post-travel serosurveillance may be helpful for such groups, or for individuals with unexplained fever. A similar approach may be justified for workers in the power and water supply industries who excavate trenches, install pipes, cables and ducting. We have encountered at least one asymptomatic seroconversion, sub-acute infection or fatal acute melioidosis in each of the above groups.

\section{Laboratory Workers}

The occupational risk of melioidosis for diagnostic laboratory workers is often overlooked. In Australia, $B$. pseudomallei is a biological safety level 2 organism and therefore does not appear to require a high level of laboratory biosecurity. But that does not mean that workers can handle it freely on the open bench. Laboratory staff who handle live $B$. pseudomallei cultures may be at risk of infection as a result of laboratory exposure $[33,34]$. Laboratory-acquired infection has been documented following gross exposure to live cultures [35], but it is possible that asymptomatic seroconversion in laboratory staff may be common but unreported. Uncommon though this is, we recommend that laboratory staff avoid sniffing culture plates to assist identification of $B$. pseudomallei by its characteristic odor. In fact, aerosolgenerating procedures with live $B$. pseudomallei cultures should be conducted in a biological safety cabinet [36]. The worker should use latex or similar protective gloves and wear a laboratory gown in accordance with good microbiology laboratory practice. For practical reasons, it may be useful to obtain baseline melioidosis serology prior to commencement of laboratory work with B. pseudomallei. This can be repeated periodically, on completion of the work or after potential exposure, according to the intensity of risk. Seroconversion (a more than four-fold increase in titer) can be used as an indication of likely exposure, and is more reliable than a single high titer. The same approach can be used with specific, highrisk occupational groups, subject to their consent and the availability of specialist interpretive advice from the public health reference laboratory running the serological tests.

\section{Biosecurity Aspects}

Threat Assessments

The biosecurity threat of melioidosis may have been overemphasized in the wake of the deliberate anthrax dispersal in the USA during late 2001 and has led to some erroneous claims about the potential disease threat [37]. Evidence for deliberate use of $B$. pseudomallei as an agent of terrorism or by a malign foreign power is lacking. We concede that the lack of a vaccine, the high level of intrinsic antibiotic resistance, infection via the respiratory route and the potential fatal outcome of melioidosis might make it appear attractive to those who intend to do harm [38]. However, we argue that the lack of person-to-person spread, the common association of comorbidity with fatal infection, the requirement for an as-yet unidentified environmental amplifier and the unpredictability of sporadic $B$. pseudomallei infection make it a poor candidate. The listing of B. pseudomallei as a category B select agent by the USA [39] may have contributed to the haste with which the initial Ceará outbreak was investigated. It is notable that 
Table 3. Melioidosis surveillance methods.

\begin{tabular}{|c|c|c|c|}
\hline Melioidosis surveillance & Sensitivity & Specificity & Comment \\
\hline Interest driven & High & Variable & $\begin{array}{l}\text { Commonest, dependent on interested individuals, } \\
\text { patchy application }\end{array}$ \\
\hline Disease notifications & Low & High & Uncommon \\
\hline Laboratory-based: culture & Low & High & Common, since often a laboratory - based diagnosis \\
\hline Laboratory-based: serology & High & Low & Commoner methods can be non-specific \\
\hline $\begin{array}{l}\text { Laboratory-based: combined } \\
\text { reference methods }\end{array}$ & High & High & $\begin{array}{l}\text { But often limited to low prevalence locations, away from } \\
\text { high endemicity areas }\end{array}$ \\
\hline Veterinary & Low & Low & May give early warning of increased human risk \\
\hline Biosecurity & High & High & Results may be restricted to government services \\
\hline
\end{tabular}

Table 4. Check list for shipping samples to melioidosis reference laboratories (NB details should be checked before shipment as specific requirements may change with increased regulation of biological material transfer and will differ according to the specific circumstances of international transfer of biological material).

\begin{tabular}{|c|c|c|c|c|}
\hline Sample & Clinical sample & Bacterial isolate & Extracted DNA & Serum \\
\hline $\begin{array}{l}\text { Initial letter of request } \\
\text { from sending laboratory }\end{array}$ & + & + & + & + \\
\hline $\begin{array}{l}\text { Letter of understanding } \\
\text { from reference laboratory }\end{array}$ & + & + & + & + \\
\hline $\begin{array}{l}\text { Import requirements } \\
\text { from receiving laboratory }\end{array}$ & + & $\begin{array}{l}+ \\
+\end{array}$ & + & + \\
\hline $\begin{array}{l}\text { Import license } \\
\text { from receiving laboratory }\end{array}$ & & & + & \\
\hline Material transfer agreement & & + & + & \\
\hline $\begin{array}{l}\text { Written confirmation of } \\
\text { absence of viable bacteria } \\
\text { in shipped sample }\end{array}$ & & & + & + \\
\hline Shipment temperature & $1-4^{\circ} \mathrm{C}$ & $1-4^{\circ} \mathrm{C}$ & $-20^{\circ} \mathrm{C}$ (dried ice $)$ & $1-4^{\circ} \mathrm{C}$ \\
\hline $\begin{array}{l}\text { Copies of all documents } \\
\text { to courier company }\end{array}$ & + & + & + & + \\
\hline $\begin{array}{l}\text { Follow-up correspondence } \\
\text { from sending laboratory } \\
\text { confirming courier tracking }\end{array}$ & nber & + & + & + \\
\hline
\end{tabular}

further occurrences of melioidosis in northeastern Brazil did not attract the same level of international attention.

\section{Laboratory Networking}

One of the consequences of $B$. pseudomallei's listing as a potential bioweapons agent has been an increased difficulty transporting live cultures of this species between public health laboratories. Clearly, the previous ad hoc approach was unsatisfactory, and the current approach is a work in progress, making it doubly difficult to cooperate in public health capacity-building across international boundaries. At present, the best way forward is careful recording of bacterial isolate transfers, defined material transfer agreements, rigorous adherence to import licensing, incorporation in registered culture collections and controlled access to archived, imported strains (Table 3). While some may find these requirements unduly restrictive, it will place more pressure on the international network of public health laboratories to use standard molecular identification and genotyping methods that can be applied to $B$. pseudomallei DNA, reducing reliance on trans-border shipment of live bacterial isolates.

\section{Emerging Public Health Issues}

We can anticipate emergence of melioidosis in a growing number of locations where the infection was previously unrecognized due to steadily-improving diagnostic capability. Filling diagnostic capability gaps will also go some way towards covering gaps in the geographic and demographic distribution of melioidosis. Targeted surveillance, where it is possible, may throw more light on high-risk activities and specific forms of occupational exposure, but until systematic surveillance based on disease notification is more widespread $[4,28,40,41]$, there will be uncertainty over the incidence of sporadic infection and the true frequency of point-source case 
clusters. In many temperate countries where melioidosis is experienced only as an imported disease, there is no strong pressure for development of an effective human vaccine. Cooperation between countries in the melioidosis endemic zone, whether relatively developed or developing, requires a more single-minded advocacy of an effective vaccine. At present, melioidosis still qualifies as a neglected tropical disease. There is another reason to collaborate in international surveillance of human melioidosis, since septicemic disease often occurs as a result of extreme weather events, some of which can be attributed to climate change. A long-term regional change in melioidosis epidemiology could serve as an indicator of effective climate change, or of direct encounters with a contaminated environment through environmental disturbance. The infection may thus provide us with an index of both direct local and indirect regional anthropogenic environmental stress.

\section{Conclusions}

Melioidosis is a complex bacterial infection that includes a cluster of overlapping disease entities, resulting from exposure to a contaminated environment. While incomplete, knowledge of the epidemiology, biology and ecology of melioidosis can be applied to improving disease surveillance, outbreak identification and environmental control. The absence of a vaccine and difficulty with both diagnosis and treatment place a heavy reliance on environmental health resources, which are often scarce in melioidosis-endemic locations. Targeted disease surveillance and selective environmental investigation represent the most effective use of those scarce public health resources, and will establish a knowledge base for introduction of a melioidosis vaccine when one eventually becomes available. International cooperation is needed for public health laboratory capacity-building and effective advocacy for vaccine development for this neglected tropical disease.

\section{References}

1. Brent A.J., Matthews P.C., Dance D.A., et al. Misdiagnosing melioidosis. Emerg Infect Dis 2007;13:349-51.

2. Dance D.A. Melioidosis: the tip of the iceberg? Clin Microbiol Rev 1991;4:52-60.

3. Melioidosis Laboratory Case Definition, Public Health Laboratory Network, Australia. http://www.health.gov.au/internet/main/ publishing.ncf/content/cda-phlncd-melioidosis.htm. 2008.

4. Currie B.J. Advances and remaining uncertainties in the epidemiology of Burkholderia pseudomallei and melioidosis. Trans R Soc Trop Med Hyg 2008;102:225-7. Epub 2007 Dec 31 .

5. Inglis T.J., Rolim D.B., Rodriguez J.L. Clinical guideline for diagnosis and management of melioidosis. Rev Inst Med Trop Sao Paulo 2006;48:1-4. Epub 2006 Mar 9.

6. Inglis T.J., Chiang D., Lee G.S., Chor-Kiang L. Potential misidentification of Burkholderia pseudomallei by API 20NE. Pathology 1998; 30:62-4.

7. Inglis T.J., Merritt A., Chidlow G., et al. Comparison of diagnostic laboratory methods for identification of Burkholderia pseudomallei. J Clin Microbiol 2005;43:2201-6.
8. Aardema H., Luijnenburg E.M., Salm E.F., et al. Changing epidemiology of melioidosis? A case of acute pulmonary melioidosis with fatal outcome imported from Brazil. Epidemiol Infect 2005;133:871-5.

9. Armstrong P.K., Anstey N.M., Kelly P.M., et al. Seroprevalence of Burkholderia pseudomallei in East Timorese refugees: implications for healthcare in East Timor. Southeast Asian J Trop Med Public Health 2005;36:1496-502.

10. Inglis T.J., Rolim D.B., Sousa A.Q. Melioidosis in the Americas. Am J Trop Med Hyg 2006; 75:947-54.

11. Suputtamongkol Y., Chaowagul W., Chetchotisakd P., et al. Risk factors for melioidosis and bacteremic melioidosis. Clin Infect Dis 1999;29:408-13.

12. Merianos A., Patel M., Lane J.M., et al. The 1990-1991 outbreak of melioidosis in the Northern Territory of Australia: epidemiology and environmental studies. Southeast Asian J Trop Med Public Health 1993;24:425-35.

13. Lim M.K., Tan E.H., Soh C.S., Chang T.L. Burkholderia pseudomallei infection in the Singapore Armed Forces from 1987 to 1994 - an epidemiological review. Ann Acad Med Singapore 1997;26:13-7.

14. Cheng A.C., Currie B.J. Melioidosis: epidemiology, pathophysiology, and management. Clin Microbiol Rev 2005; $18: 383-416$

15. Howe C., Sampath A., Spotnitz M. The pseudomallei group: a review. J Infect Dis 1971;124:598-606.

16. Tan G.Y., Liu Y., Sivalingam S.P., et al. Burkholderia pseudomallei aerosol infection results in differential inflammatory responses in BALB/c and C57Bl/6 mice. J Med Microbiol 2008;57:508-15.

17. Currie B.J., Jacups S.P. Intensity of rainfall and severity of melioidosis, Australia. Emerg Infect Dis 2003;9:1538-42.

18. Cheng A.C., Jacups S.P., Gal D., et al. Extreme weather events and environmental contamination are associated with case-clusters of melioidosis in the Northern Territory of Australia. Int J Epidemiol 2006;35:323-9. Epub 2005 Dec 2.

19. Allworth A.M. Tsunami lung: a necrotising pneumonia in survivors of the Asian tsunami. Med J Aust 2005; $182: 364$.

20. Inglis T.J.J., Levy A., Merritt A.J., et al. Melioidosis risk in a tropical industrial environment. Am J Trop Med Hyg 2009;80:78-84.

21. McCormick J.B., Sexton D.J., McMurray J.G., et al. Human-tohuman transmission of Pseudomonas pseudomallei. Ann Intern Med 1975;83:512-3.

22. Kunakorn M., Jayanetra P., Tanphaichitra D. Man-to-man transmission of melioidosis. Lancet 1991;337:1290-1.

23. Inglis T.J., Garrow S.C., Henderson M., et al. Burkholderia pseudomallei traced to water treatment plant in Australia. Emerg Infect Dis 2000;6:56-9.

24. Currie B.J., Mayo M., Anstey N.M., et al. A cluster of melioidosis cases from an endemic region is clonal and is linked to the water supply using molecular typing of Burkholderia pseudomallei isolates. Am J Trop Med Hyg 2001;65:177-9.

25. Rolim D.B., Vilar D.C., Sousa A.Q., et al. Melioidosis, northeastern Brazil. Emerg Infect Dis 2005;11:1458-60.

26. Ketterer P.J., Webster W.R., Shield J., et al. Melioidosis in intensive piggeries in south eastern Queensland. Aust Vet J 1986;63:146-9.

27. Inglis T.J., Garrow S.C., Adams C., et al. Dry-season outbreak of melioidosis in Western Australia. Lancet 1998;352:1600.

28. Inglis T.J., Foster N.F., Gal D., et al. Preliminary report on the northern Australian melioidosis environmental surveillance project. Epidemiol Infect 2004;132:813-20.

29. Howard K., Inglis T.J. Disinfection of Burkholderia pseudomallei in potable water. Water Res 2005;39:1085-92.

30. Currie B., Smith-Vaughan H., Golledge C., et al. Pseudomonas pseudomallei isolates collected over 25 years from a nontropical endemic focus show clonality on the basis of ribotyping. Epidemiol Infect 1994;113:307-12.

31. Inglis T.J.J., Buller N.F. Where have all the pathogens gone? Results of re-sampling at a persistent enzootic melioidosis locus. World Melioidosis Congress, Perth, Western Australia. 26-29 th September, 2001. 
32. Nachiangmai N., Patamasucon P., Tipayamonthein B., et al. Pseudomonas pseudomallei in southern Thailand. Southeast Asian J Trop Med Public Health 1985;16:83-7.

33. Centers for Disease Control and Prevention (CDC). Laboratory exposure to Burkholderia pseudomallei-Los Angeles, California, 2003. MMWR Morb Mortal Wkly Rep 2004;53:988-90.

34. Rusnak J.M., Kortepeter M.G., Hawley R.J., et al. Risk of occupationally acquired illnesses from biological threat agents in unvaccinated laboratory workers. Biosecur Bioterror 2004; $2: 281-93$.

35. Schlech W.F. 3rd, Turchik J.B., Westlake R.E. Jr., et al. Laboratoryacquired infection with Pseudomonas pseudomallei (melioidosis). N Engl J Med 1981;305:1133-5.

36. Ashdown L.R. Melioidosis and safety in the clinical laboratory. J Hosp Infect. 1992; 21: 301-6.

37. Cheng A.C., Dance D.A., Currie B.J. Bioterrorism, Glanders and melioidosis. Euro Surveill 2005;10:E1-2; author reply E1-2.
38. Bossi P., Tegnell A., Baka A., et al. Task Force on Biological and Chemical Agent Threats, Public Health Directorate, European Commission, Luxembourg. Bichat guidelines for the clinical management of glanders and melioidosis and bioterrorism-related glanders and melioidosis. Euro Surveill 2004;9:E17-8.

39. http://www.selectagents.gov/agentToxinList.htm.2008.

40. Chou D.W., Chung K.M., Chen C.H., Cheung B.M. Bacteremic melioidosis in southern Taiwan: clinical characteristics and outcome. J Formos Med Assoc 2007;106:1013-22.

41. Poulose V. Severe community-acquired pneumonia requiring intensive care: a study of 80 cases from Singapore. Singapore Med J 2008;49:458-61.

42. Sam I.C., Puthucheary S.D. Melioidosis in children from Kuala Lumpur, Malaysia. Ann Trop Paediatr 2006;26:219-24.

43. Edmond K.M., Bauert P., Currie B.J. Paediatric melioidosis in the Northern Territory of Australia: an expanding clinical spectrum. J Paediatr Child Health 2001;37:337-41. 